Histoire de l'éducation

$121 \mid 2009$

Varia

\title{
GUIBERT-FOURRÉ (Florence), La Géographie de nos
} grands-mères

Paris : Archives \& Culture, 2008. 71 p. (coll. « Images d'autrefois »)

Nicolas Ginsburger

\section{OpenEdition}

Journals

Édition électronique

URL : https://journals.openedition.org/histoire-education/1804

DOI : $10.4000 /$ histoire-education. 1804

ISSN : 2102-5452

Éditeur

ENS Éditions

Édition imprimée

Date de publication : 1 janvier 2009

Pagination : 130-132

ISBN : 979-2-7342-1142-6

ISSN : 0221-6280

\section{Référence électronique}

Nicolas Ginsburger, « GUIBERT-FOURRÉ (Florence), La Géographie de nos grands-mères », Histoire de l'éducation [En ligne], 121 | 2009, mis en ligne le 20 mai 2009, consulté le 20 mai 2021. URL : http:// journals.openedition.org/histoire-education/1804; DOI : https://doi.org/10.4000/histoire-education. 1804

Ce document a été généré automatiquement le 20 mai 2021.

(c) Tous droits réservés 


\section{GUIBERT-FOURRÉ (Florence), La Géographie de nos grands-mères}

Paris : Archives \& Culture, 2008. 71 p. (coll. «Images d'autrefois »)

Nicolas Ginsburger

\section{RÉFÉRENCE}

GUIBERT-FOURRÉ (Florence), La Géographie de nos grands-mères, Paris : Archives \& Culture, 2008. 71 p. (coll. «Images d'autrefois »)

1 Au-delà de l'aspect naïf et nostalgique de son titre et de sa couverture (deux écolières à l'air très sage lisent, une troisième dessine une carte de France au tableau noir), La Géographie de nos grands-mères est un album agréable et très bien illustré consacré à l'histoire de la géographie scolaire dans l'enseignement primaire français, des débuts de la IIIe République à nos jours. L'essai introductif, écrit par Florence Guibert-Fourré, professeur d'histoire-géographie, documentaliste et écrivain, long de 40 pages, a pour but de dépasser le débat sur la baisse du niveau scolaire pour étudier les caractéristiques de l'enseignement de la géographie à la Belle Époque, ses évolutions au cours du XXe siècle et les "visions du monde » sous-jacentes. Pour cela, pas de bibliographie ni d'utilisation explicite de travaux récents, comme ceux d'Isabelle Lefort ${ }^{1}$, mais des sources diverses : citations des programmes officiels, de manuels de géographie, d'entretiens avec d'anciens élèves, mais surtout, et c'est là une grande qualité de l'ouvrage, de très nombreuses reproductions commentées de cahiers et de travaux d'écoliers et de collégiens (leçons, dictées, cartes manuscrites) de différentes époques allant de 1920 à 2006 (dont l'origine n'est cependant pas indiquée).

2 F. Guibert-Fourré analyse d'abord ce qu'elle appelle «la pédagogie de grandmaman ", fondée sur "l'inventaire de la terre " (usage intensif de la mémoire pour l'apprentissage de listes, emboîtement des espaces), puis dessine l'idéologie patriotique et républicaine de la géographie scolaire du début du XXe siècle. La dernière partie de l'essai, plus originale, est consacrée à «l'imaginaire géographique » véhiculé par les 
cartes et les documents d'étude, mais aussi aux usages par les élèves de leurs manuels, véritables "livres pour rêver" grâce à la complémentarité entre le texte et les illustrations.

3 L'analyse, souvent bien présentée et claire, à défaut d'être très surprenante, conclut sur le constat d'une triple évolution: un allègement des contenus au profit d'une démarche plus active de réflexion et de construction des savoirs de la part de l'élève, des changements dans l'idéologie, enfin un "désenchantement» de la géographie scolaire, par la disparition de l'unité matérielle du manuel pour un savoir et un apprentissage fragmentés (photocopies, fiches d'activités), en concurrence avec d'autres sources d'informations que celles de l'école. L'ensemble est intéressant bien que parfois superficiel, par exemple concernant les évolutions idéologiques et pédagogiques récentes, notamment les usages d'autres supports que le livre suite à l'apparition de nouvelles technologies comme la télévision, l'informatique ou Internet.

4 Liée à cet essai, la belle reproduction intégrale du manuel de Pierre Foncin pour le cours préparatoire, publié en 1910 par Armand Colin, donne une idée du type d'ouvrage utilisé dans les écoles au début du XXe siècle: texte et exercices sous forme de questions-réponses, nombreuses illustrations (schémas, cartes à diverses échelles, dessins colorés, paysages pittoresques). Ce livre est cependant marqué par la forte personnalité de son auteur, bien connu des historiens de la géographie française: Pierre Foncin (1841-1916), inspecteur général de l'Instruction publique, spécialiste de géographie historique, mais aussi soutien ardent de la colonisation française, cofondateur et président de l'Alliance française (ce qui explique l'accent mis sur les colonies françaises dans son ouvrage) et partisan actif du régionalisme (la présentation de la liste des départements, répartis non selon l'ordre alphabétique, mais dans le cadre d'une partition du territoire national en dix grandes zones, est un choix révélateur), engagement que partageait son ami et collègue Paul Vidal de la Blache. À cet égard, même si l'essai introductif est illustré de quelques pages du Tour de la France par deux enfants de G. Bruno (1877), il aurait été intéressant de reproduire, au moins en partie, d'autres manuels diffusés à la même époque pour en montrer les points communs et les différences avec celui de P. Foncin.

\section{NOTES}

1. La Lettre et l'esprit, géographie scolaire, géographie savante, 1870-1970, Paris, Presses du CNRS, 1992. 


\section{AUTEURS}

NICOLAS GINSBURGER 